


\title{
Mechanically Induced Cracking Behaviour in Fine and Coarse Sand Strain Hardening Cement Based Composites (SHCC) at Different Load Levels
}

\author{
Suvash Chandra Paul ${ }^{1}$ and Gideon P. A. G. van Zijl ${ }^{2}$
}

Received 2 May 2013, accepted 11 November 2013

doi:10.3151/jact.11.301

\begin{abstract}
This research paper describes the development of strain hardening cement based composite (SHCC) with mostly local ingredients available in Stellenbosch, South Africa, and subsequent characterisation of crack distributions under various loading conditions. The mechanical induced cracking behaviour of SHCC containing local coarse sand (CS) (particle size up to $2.36 \mathrm{~mm}$ ) is reported and compared with SHCC containing specially graded local fine sand (FS) (particle size up to $300 \mu \mathrm{m}$ ). Crack width distributions, obtained by digital image correlation, in direct tension at various average strain levels are presented for both FS and CS-SHCC dumbbell specimens. Both these SHCC types were also used to prepare beam specimens, both unreinforced and reinforced with steel bar at two reinforcement levels and with three cover depths. Both sand types could be used successfully for SHCC, achieving strain hardening and crack width and spacing control.
\end{abstract}

\section{Introduction}

Internationally, the cost of maintenance and rehabilitation of infrastructure is growing, and has reached roughly $50 \%$ of total construction expenditure in many countries. Crack control and crack width limitation is a well-established concept in durability of concrete structures. This paper introduces a fibre-reinforced cementbased composite (FRC), which exhibits increased tensile resistance after crack initiation. The main feature of this new type of material, so-called strain hardening cement-based composite (SHCC), is the formation of multiple fine cracks and increased or maintained tensile resistance whilst the next cracks appear (Li et al. 1993). This can be achieved with relatively low volumes of discontinuous, short fibres, and usual mixing and casting procedures. Applications of this class of material include bonded overlay constructions or repairs like composite bridge decks and dam faces, and as energy dissipating structural elements in seismic regions, for instance coupling beams and floors in tall buildings.

The presence of large cracks in reinforced concrete structures is a major cause of corrosion damage, leading to significant reduction in service life of concrete structures. Several causes of cracks in concrete exist, including shrinkage, settlement, actions like seismic events or mere mechanical service loads. It is believed that control of the crack widths to remain below threshold levels slow down deterioration processes like corrosion sig-

${ }^{1} \mathrm{PhD}$ candidate, University of Stellenbosch, Department of Civil Engineering, Matieland, South Africa.

${ }^{2}$ Professor, University of Stellenbosch, Department of Civil Engineering, Matieland, South Africa.

E-mail: gvanzijl@sun.ac.za nificantly. In conventional reinforced concrete crack widths are usually controlled by sound detailing of reinforcing steel, but this may lead to extra reinforcing steel, tedious construction processes and associated additional cost. The use of SHCC, which inherently controls crack widths, may be an alternative to protect reinforcing steel from such deterioration processes.

The major advantage of SHCC to normal concrete (NC) is the formation of multiple fine cracks. Fine cracks have been shown to delay ingress of liquids and salts into the SHCC (Wang et al. 1997; Sahmaran et al. 2007; Mihashi et al. 2011). Evidence has emerged that water (Zhang et al. 2010) and chloride (Paul et al. 2013c) penetrate even fine cracks relatively quickly, but corrosion rates in steel bars embedded in cracked SHCC are low (Miyazato and Hiraishi 2005; Mihashi et al. 2011). This is why it is thought that SHCC may delay the corrosion process of steel in R/SHCC structures and increase the total life span, or reduce life cycle cost.

Several works have shown that multiple fine cracks with average widths in the range 50 to $80 \mu \mathrm{m}$ arise in SHCC for a large range in tensile strain (eg. Weimann and Li 2003; Wang and Li 2006; Paul and van Zijl $2013 b)$. It has recently been reported that the maximum crack widths in such specimens may be higher, in the range of about 0.1 to $0.3 \mathrm{~mm}$ (Van Zijl 2011). In SHCC beam specimens the average crack widths remain below $100 \mu \mathrm{m}$ even at ultimate load (Paul and van Zijl 2013b,c). Multiple, fine cracking was observed in SHCC by several researchers (Fischer and Li 2002; Sahmaran 2008; Ahmed 2012, 2013), but detailed crack width characterisations were not included. In this paper, more light is shed on cracking in SHCC in uniaxial tension, as well as steel bar reinforced SHCC (R/SHCC) in flexure, for its importance in structural durability.

Another important issue is that most research on 
SHCC is based on fine sand (FS), with particle sizes up to 0.2 or $0.3 \mathrm{~mm}$ which require special and expensive pre-grading to ensure quality (Li et al. 1993; Wittmann et al. 2009; Adendorff et al. 2009). Here the development of SHCC with mostly local ingredients is presented, and the behaviour of SHCC containing local coarse sand (CS) with particle size up to $2.36 \mathrm{~mm}$ is compared to that of FS-SHCC. Sucessful application of CS-SHCC can reduce the cost considerably. More than $3 \%$ tensile strain can be achieved by using CS in SHCC (Paul and van Zijl 2013b). This 3\% strain exceeds that of concrete by several orders, and also exceeds the yield strain of reinforcing steel, which makes SHCC and reinforcing steel compatible in the inelastic range, avoiding destructive premature delamination in R/SHCC. Results of direct tensile and three point bending tests on both FS and CS-SHCC are reported.

\section{Significance of the research}

Limited information and knowledge are the main obstacles to using SHCC in the bulk structures. This motivated the current study, with the focus on artificial induction of cracking in SHCC in order to characterise what is considered to be its most important feature and mechanism of resistance to deterioration processes. The outcome of this research is intended to provide the basis for application of SHCC in structures where crack width control is crucial for resistance to deterioration processes like corrosion of reinforcing steel. In addition to improved structural durability performance, the work aims to evaluate the use of natural sand, which includes significantly larger particle sizes than used in the development of SHCC thus far. This will significantly reduce the cost of this advanced cement-based class of materials.

\section{Background and strain hardening theory of SHCC}

Recently developed advanced cement-based materials like high strength concrete (HSC), ultra-high strength concrete (UHSC), or high performance (HPC) and ultrahigh performance (UHPC) concretes have shown drastic improvement in compressive strength, E-modulus, flexural strength as well as tensile strength (Richard 1994; Benjamin 2006; Saravanan 2010). However, one of the major disadvantages of these types of concretes is a low tensile strain capacity or ductility. Ductility is a very important parameter for structures, especially structures in seismic regions and harsh environments. Therefore, the designer needs to provide extra reinforcement in such structures for enough ductility which is often very costly, and in some cases also not sufficient to prevent significant damage or collapse. One of the major advantages of the SHCC is that it has higher ductility than normal concrete (NC), HSC and UHSC. Using SHCC, it is possible to get more than $3-5 \%$ tensile strain at full or increased post-crack tensile resistance, while the ultimate strain in NC is about $0.015-0.02 \%$. In spite of the fact that the initial cost of the SHCC is higher than that of $\mathrm{NC}$, it may be balanced by reducing intervention cost in future. The $300-500 \%$ higher ultimate strain of SHCC may improve resistance tot chemical and seismic action. So, it may be possible to reduce the amount of extra reinforcement needed for ductility in structures, and the life cycle cost may be reduced in harsh environments.

Carefully balanced cement-based matrix and fibre properties in SHCC improve crack bridging capacity. This results in pseudo strain hardening, or increased tensile resistance with increased tensile deformation beyond the first cracking stress. By successful crack bridging, successive cracking occurs at next weakest points in the matrix, leading to multiple crack formation in SHCC. Strain hardening is achieved by fulfilling the following conditions (Li et al. 1993, 1995, 2002):

- The crack tip toughness should be equal or less than complementary energy $\left(J_{t i p} \leq J_{b}{ }^{\prime}\right)$.

- Steady state cracking must be achieved rather than Griffith type cracks.

To realise the above, it is required that

- A critical fibre volume is used $\left(V_{f} \geq V_{f}^{\text {crit }}\right)$.

- Fibers experience bond-slip in the matrix during the multiple crack formation phase, rather than rupture.

The tensile response as well as the micro-crack formation in SHCC will differ in different composites because of various percentages of fibre volume $\left(V_{f}\right)$, aggregate to binder ratio $(a / b)$, water to binder ratio $(w / b)$, type and amount of binder and aggregate.

In addition to the stated requirements for strain hardening, appropriate packing of aggregates and distribution of fibres are considered essential for achieving strain hardening. In reality, several factors influence fibre dispersion and orientation. Fibres will not distribute in a described way due to their discontinuous nature, the production process, but also due to ratios of fibre length to particle size and fibre spacing to particle size. The role of fibre spacing to particle size is investigated here. Within a range of suitable fibre length to particle size ratios and for particle sizes smaller than the average fibre spacing, fibres may distribute in a regular pattern in a good production process and mix consistency. Such a regular dispersion is believed to be highly preferred, if not a physical requirement for fibre crack-bridging efficiency towards multiple crack formation and strain hardening. Fibre spacing $(S)$ in a regular grid of aligned fibres with circular cross-section can be shown from simple geometrical relations to be given by

$$
S=d_{f}\left(\sqrt{\frac{\pi}{4 A_{f}}-1}\right)
$$

where $A_{f}$ is the ratio of total area of fibres in a crosssection to the cross-section area and $d_{f}$ is the fibre di- 
ameter. Fibre spacing in concrete was also proposed by several other authors (eg. Kelly 1974; McKee 1969; Romualdi and Mendal 1964). Eq. (2) was proposed by Kelly (1974):

$$
S=d_{f}\left(\sqrt{\frac{\alpha}{V_{f}}-1}\right)
$$

where $V_{f}$ is the fibre volume content ratio and $\alpha=\pi / 2 \sqrt{ } 3$ for a regular triangular fibre array and $\pi / 4$ for a regular square fibre array. McKee (1969) and Mindess and Young (1981) respectively proposed equations (3) and (4) for random oriented short fibres of length $L_{f}$ and diameter $d_{f}$.

$$
\begin{aligned}
& S=\sqrt[3]{\frac{\pi d_{f}^{2} L_{f}}{4 V_{f}}} \\
& S=0.138 d_{f} \frac{\sqrt{L_{f}}}{V_{f}}
\end{aligned}
$$

The fibre spacings given by eqs. (1) to (4) will be considered in the discussion of FS and CS-SHCC investigated in this research in subsequent sections.

\section{Experimental design}

Table 1 shows the composition of materials used in this study. CEM I 52.5 cement, class F Fly ash, fine grain Phillippi sand (graded to ASTM F95) as FS and coarse natural Malmesbury sand were used as CS. PVA fibres with specification $L_{f}=12 \mathrm{~mm}, d_{f}=40 \mu \mathrm{m}, E_{f}=40$ $\mathrm{kN} / \mathrm{mm}^{2}$ together with Dynamo SP1 super plasticizer (SP), viscous agent (VA) and air-entraining agent (AEA) were used to ensure good fibre distribution and associated formation of multiple cracks in SHCC.

After performing several trial mixes on SHCC with FS and CS, four mix designs were chosen for FS and CS-SHCC, as shown in Table 1. The mixes of FSSHCC contain a maximum particle size of just over 300 $\mu \mathrm{m}$. CS-SHCC1 to 3 contain CS with maximum particle size up to $2.36 \mathrm{~mm}$ and CS-SHCC4 contains a maximum particle size of $1.70 \mathrm{~mm}$. Figure 1 shows the size distribution gradings of both FS and CS. Small dumbbell shaped specimens, with a cross section of $30 \pm 2 \mathrm{~mm}$ $\mathrm{x} 16 \pm 2 \mathrm{~mm}$ in the $80 \mathrm{~mm}$ gauge length as shown in Fig. 2 were made for the direct tensile test. Cubes with 100 $\mathrm{mm}$ side length and cylinders with $100 \mathrm{~mm}$ diameter and $200 \mathrm{~mm}$ length were made to determine the compressive strength and E-modulus of the SHCC. Beams with dimensions of $100 \mathrm{~mm} \times 100 \mathrm{~mm}$ x $500 \mathrm{~mm}$ were prepared for the flexural test. Slump flow and air content tests were also performed, and their results are summarised in Table 2. All the specimens (dumbbells, cubes, cylinders and beams) were covered with plastic sheet until the de-moulding, approximately 48 hours after casting. After de-moulding, specimens were kept in a water curing tank at $21 \pm 3^{\circ} \mathrm{C}$ until the testing day.

For accurate determination of the compressive strength and E-modulus of the matrix, a $2500 \mathrm{kN}$ capacity Contest Testing Machine was used together with a $500 \mathrm{kN}$ load cell and two linear variable differential transformers (LVDT). A Zwick Z250 material testing machine was used to perform direct tension tests of the dumbbell specimens at a constant deformation rate of $0.0075 \mathrm{~mm} / \mathrm{s}$ of the $80 \mathrm{~mm}$ gauge length. In total 24 specimens from each set of FS and CS at 14 and 28 days

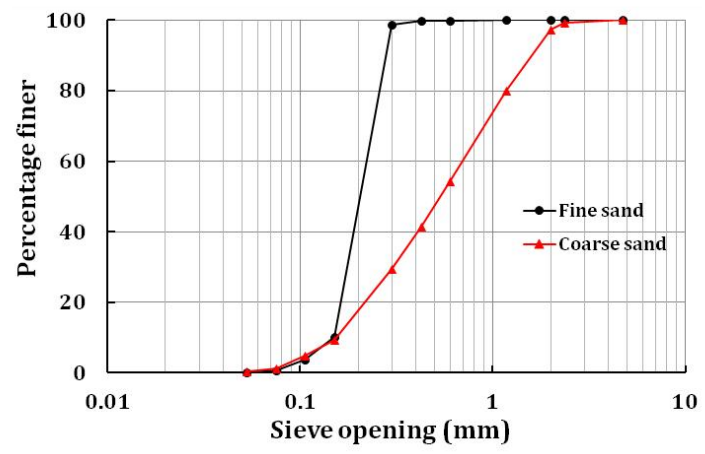

Fig. 1 Particles size distribution of FS and CS.

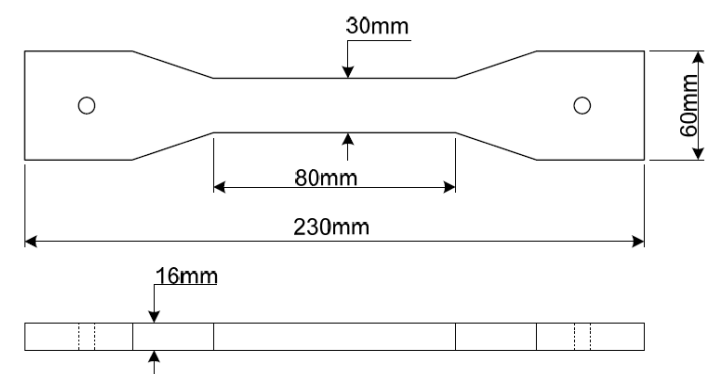

Fig. 2 Dumbbell specimen used in the direct tensile test.

Table 1 Mix ingredient materials $\left(\mathrm{kg} / \mathrm{m}^{3}\right)$ used in SHCC.

\begin{tabular}{|c|c|c|c|c|c|c|c|c|c|}
\hline \multicolumn{2}{|c|}{ Materials } & Cement & Fly-ash & Sand & Water & Fibre (\%) & SP & VA & AEA \\
\hline \multirow{3}{*}{ FS-SHCC } & 1 & 441 & 657 & 539 & 387 & 2.16 & 1.89 & 0.95 & 0.51 \\
\cline { 2 - 11 } & 2 & 445 & 662 & 544 & 390 & 1.48 & - & 0.97 & 0.52 \\
\cline { 2 - 11 } & 3 & 447 & 665 & 546 & 392 & 0.99 & - & 0.97 & 0.53 \\
\cline { 2 - 11 } & 4 & 392 & 674 & 553 & 392 & 2.01 & 1.99 & 1.00 & 0.54 \\
\hline \multirow{3}{*}{ CS-SHCC } & 1 & 442 & 658 & 540 & 388 & 1.96 & 2.54 & 0.95 & 0.51 \\
\cline { 2 - 11 } & 2 & 445 & 662 & 544 & 390 & 1.48 & - & 0.96 & 0.52 \\
\cline { 2 - 10 } & 3 & 447 & 665 & 546 & 392 & 0.99 & - & 0.97 & 0.53 \\
\cline { 2 - 11 } & 4 & 392 & 674 & 553 & 392 & 2.01 & 1.99 & 1.00 & 0.54 \\
\hline
\end{tabular}

Note: These are the relative weight $/ \mathrm{m}^{3}$ with assuming air content $5 \%$ in the mix. Relative density of PVA fibre is 1.3 , so $1 \%$ fibre is equivalent to $13 \mathrm{~kg} / \mathrm{m}^{3}$. 
Table 2 Fresh and mechanical properties of SHCC matrix.

\begin{tabular}{|c|c|c|c|c|c|c|c|}
\hline & Mix nr & Slump (mm) & $\%$ of Air & $\mathrm{f}_{\mathrm{cu}}(\mathrm{MPa})$ & E-mod (GPa) & $\sigma_{\mathrm{u}, \mathrm{st}}(\mathrm{MPa})$ & $\varepsilon_{\max }(\%)$ \\
\hline \multirow{4}{*}{ FS-SHCC } & 1 & $170-200$ & $4.5-6.5$ & 39 & 20 & $4.05(3.41)$ & $1.48(3.1)$ \\
\hline & 2 & 185 & - & 34 & 16 & 3.47 & 1.16 \\
\hline & 3 & 190 & - & 34 & 18 & 2.46 & 0.86 \\
\hline & 4 & $200-230$ & - & 29 & 13 & $-(2.76)$ & $-(2.93)$ \\
\hline \multirow{4}{*}{ CS-SHCC } & 1 & $170-200$ & $4.5-8.9$ & 35 & 18 & $3.32(3.24)$ & $1.46(2.8)$ \\
\hline & 2 & 185 & - & 31 & 13 & 3.27 & 1.14 \\
\hline & 3 & 173 & - & 37 & 19 & 2.28 & 0.76 \\
\hline & 4 & $195-225$ & - & 25 & 14 & $-(2.67)$ & $-(1.52)$ \\
\hline
\end{tabular}

Note: Except slump and air value, these are mostly 28 days results (and at 14 days in brackets).
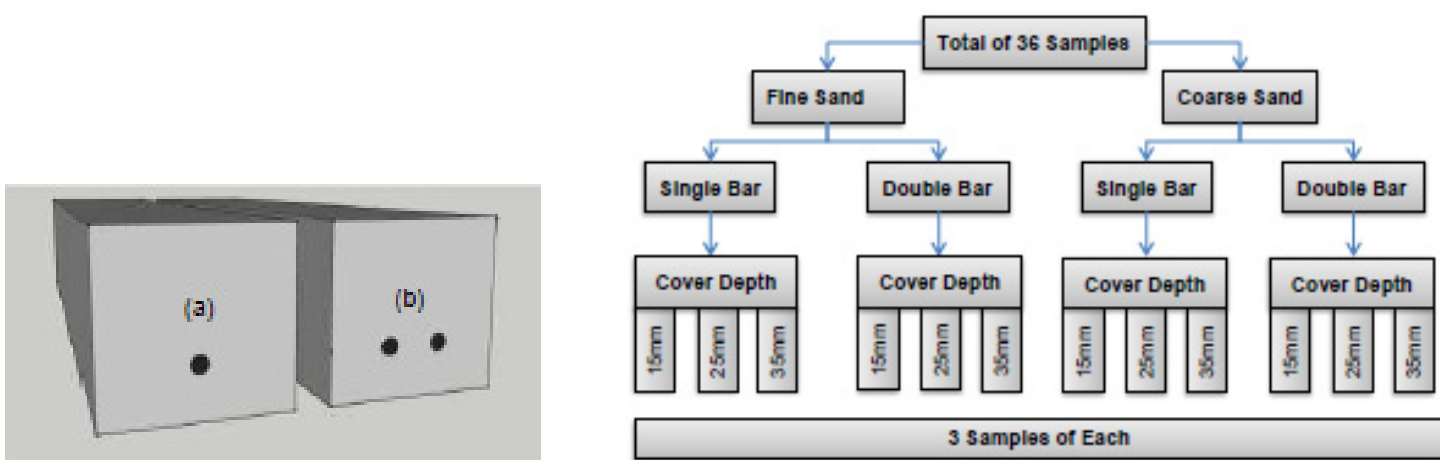

Fig. 3 Details of research plan, showing number of specimens, reinforcement and cover depth of R/SHCC.

were tested respectively. The number of cracks and crack widths in the dumbbell specimens were determined using a contactless deformation measurement system ARAMIS. The details of this measuring system can be found in Nieuwoudt (2012).

In the case of the flexural tests on SHCC and $\mathrm{R} / \mathrm{SHCC}$, a constant loading rate of $0.03 \mathrm{kN} / \mathrm{s}$ was maintained for all specimens. For SHCC specimens (without steel bar), ultimate load (for FS and CSSHCC1) and load up to a deflection level of $1 \mathrm{~mm}$ was applied (for FS and CS-SHCC4) at the age of 28 days after casting and cracks were monitored at these respective load levels. R/SHCC specimens (with steel bar) were made from both FS and CS-SHCC4 mixes and loaded up to a vertical deflection level of $3.5 \mathrm{~mm}$ to form enough cracks in the specimens. These specimens were tested at the age of 14 days after casting. It is worth mentioning that these $\mathrm{R} / \mathrm{SHCC} 4$ specimens are currently used further for chloride induced corrosion testing, which is ongoing and not reported further here. In these R/SHCC4 specimens, single and double steel bars were used in both types of sand at three different cover depths (15 mm, $25 \mathrm{~mm}$ and $35 \mathrm{~mm}$ ). In total 48 beam specimens were prepared for testing, comprising the following: 3 specimens each of FS-SHCC1, FSSHCC4, CS-SHCC1 and CS-SHCC4; 18 specimens each of R/FS-SHCC4 and R/CS-SHCC4. The details of cover depth, number of specimens and steel bar are shown in Fig. 3.

\section{Experimental results}

The results in terms of fresh mortar and SHCC properties, mechanical properties in the hardened state at the ages 14 and 28 days, as well as crack distributions are given in the following sections.

\subsection{Slump flow and air content of SHCC matrix}

The fresh properties such as slump flow value and the percentage of air results are shown in Table 2. For FS and CS-SHCC the flow range was $170-230 \mathrm{~mm}$. Figure 4 shows the flow behaviour of both SHCC mixes. It must be noted that the shown CS-SHCC flow was obtained for a slightly lower fibre content $(1.96 \%$ by volume) than for the FS-SHCC (2.16\%), as given in Table 1. The combination of coarse sand and fibre led to reduced flow. Due to the importance of good flowability for fibre dispersion ( $\mathrm{Li} 1993,2002)$, the lower fibre volume was accepted for CS-SHCC, leading to similar flow ranges for FS-SHCC and CS-SHCC. The variation in results for a particular mix is ascribed to different batches of SHCC for different specimens (dumbbell, beam, cube and cylinder).

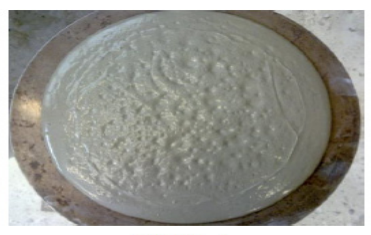

FS-Mortar

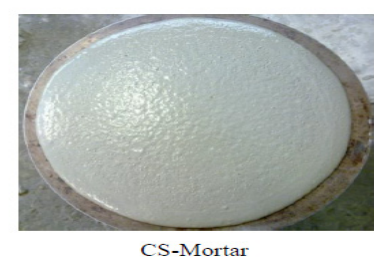

Fig. 4 Flow of SHCC and Mortar matrix.

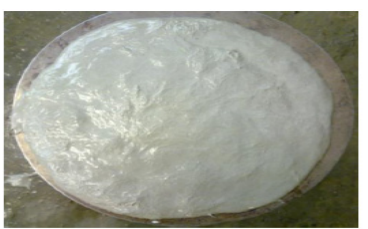

FS-SHCC

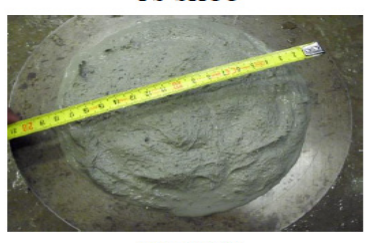

$\mathrm{CS}-\mathrm{SHCC}$ 


\subsection{Influence of particle size in fibre distribution} The spacing of the $12 \mathrm{~mm}$ long and $0.04 \mathrm{~mm}$ diameter PVA fibre used in this research was predicted for both mix 1 and 4 of FS-SHCC and CS-SHCC by using eqs. (1) to (4). It was found that the range of fibre spacings in both SHCC are 0.24 to $0.25 \mathrm{~mm}$ (using eqs 1 and 2) and 0.89 to $0.95 \mathrm{~mm}$ (using Eqs 3 and 4) respectively, as shown in Fig. 5. The values obtained from Eqs $1 \& 2$ are considered to be lower limits to fibre spacing, as they in fact represent the spacing of dispersed continuous fibres. Short, randomly oriented fibres have larger

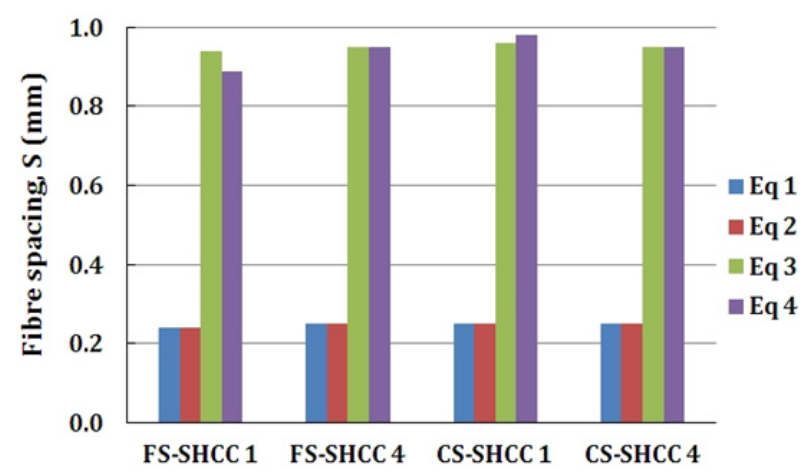

Fig. 5 Fibre spacing in different SHCC mixes.
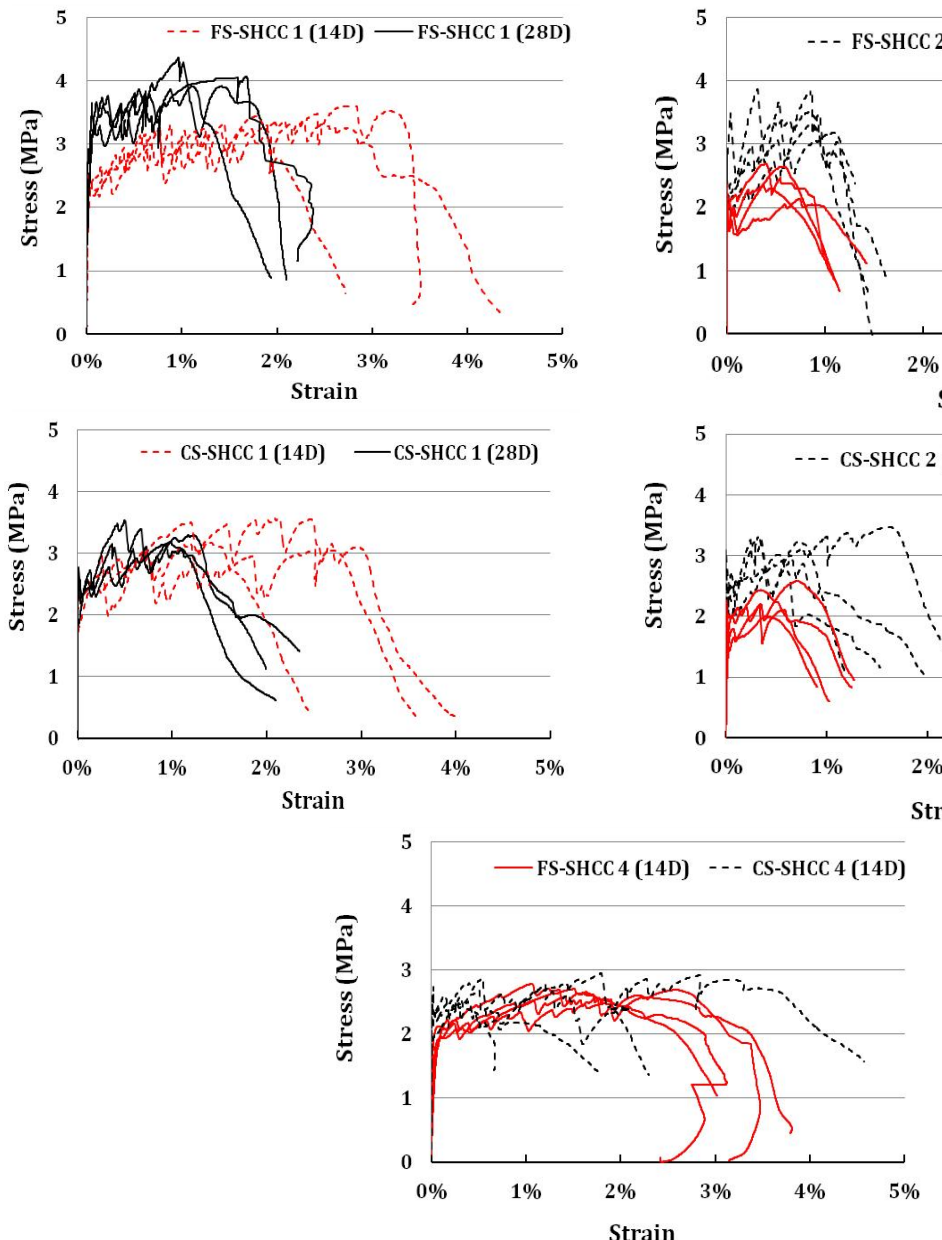

Fig. 6 SHCC response in direct tensile test (Paul and van Zijl, 2013a,b,c). spacing which can be seen in the values obtained from Eqs 3 and 4. It can be said that in FS-SHCC and CSSHCC, a particle size larger than roughly $0.9 \mathrm{~mm}$ will disturb the regular distribution pattern of fibres. Since almost $98 \%$ of FS particles of both mixes 1 and 4 by weight pass through a sieve opening of $0.3 \mathrm{~mm}$, it can be assumed that the fibre distribution in FS-SHCC will create a regular pattern, if good dispersion is ensured in the mix design and process. On the other hand about $45 \%$ of the CS particles by weight is retained on the 0.6 $\mathrm{mm}$ sieve, representing $0.5 \%$ of the total number of particles in the CS. In total about $19 \%$ of the CS particles by weight, or $0.04 \%$ of the total number of particles are larger than $1.18 \mathrm{~mm}$ (see the grading in Fig. 1). Although the number of particles exceeding the even particle spacing of roughly $0.9 \mathrm{~mm}$ is relatively low, it will disturb the regular fibre dispersion and may lead to lower ultimate tensile strain.

\subsection{Tensile stress and strain of SHCC}

The typical direct tensile stress and strain responses of SHCC's containing various fibre volumes at different ages are shown in Fig. 6. In total 3 specimens for Type 1 FS-SHCC and CS-SHCC each were tested at ages 14 and 28 days, and 4 of each for types $2-4$. Their average
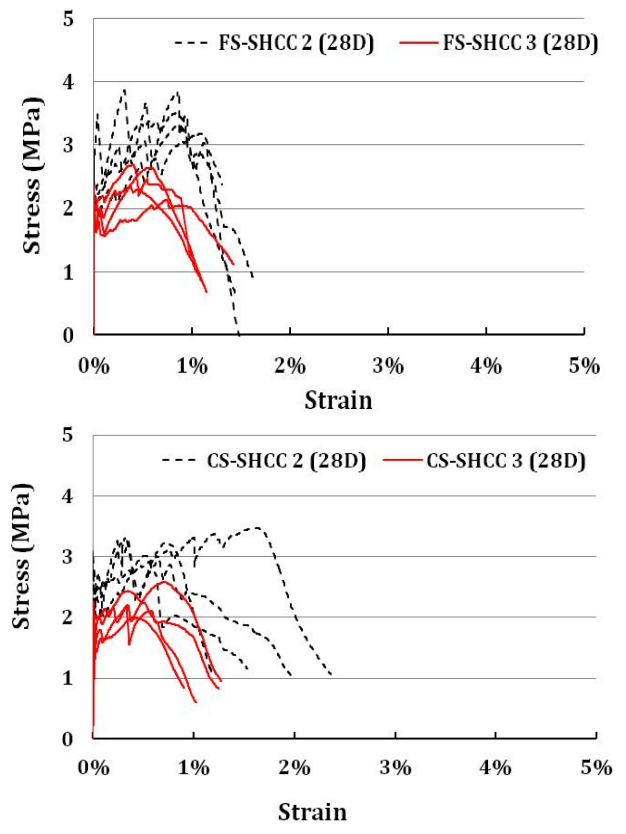
ultimate tensile strength $\left(\sigma_{\mathrm{u}, \mathrm{st}}\right)$ and strain $\left(\varepsilon_{\max }\right)$ are summarised in Table 2. Recall that FS-SHCC1 has slightly higher fibre content $(2.16 \%)$ than CS-SHCC1 at $1.96 \%$, as demanded by the flowability of the respective mixes.

In both FS and CS-SHCC1, the 14 days ultimate strain was significantly higher than at the age of 28 days, while the 28 day ultimate tensile strength increased slightly from 14 days to 28 days. So the experimental results show that these particular SHCC's become more brittle in direct tensile at higher age. This trend was also found by Wang and Li (2006) and Yang et al. (2005). This requires further mix improvement to reduce such embrittlement with aging, which is a topic of continued research by the authors. Also, the strain capacity of SHCC is influenced by the aggregate binder ratio (A/B), aggregate content and grading of aggregates (van Zijl 2005). Table 2 indicates a roughly 19\% and 2\% higher tensile strength and $52 \%$ and $92 \%$ lower ultimate strain for FS-SHCC1 and CS-SHCC1 at 28 days than 14 days. Table 2 also shows an 11\% higher compressive strength $\left(f_{\mathrm{cu}}\right)$ and E-modulus (E-mod) for FS-SHCC1 than for CS-SHCC1. Slightly lower average ultimate tensile stress and strain values were observed for CS-SHCC compared to FS-SHCC. This is ascribed to the fibre spacing disturbance in CS-SHCC as explained in the previous section.

\subsection{Number of cracks and crack width in SHCC}

This section reports detailed crack distributions in FSSHCC1 and CS-SHCC1 tested at the age of 14 days, measured on 3 specimens of each SHCC type, at various strain levels as indicated in Fig. 7.

From Fig. 7 it appears that the most cracks have widths below $100 \mu \mathrm{m}$ for the full strain range (3\% for FS-SHCC and $2.5 \%$ for CS-SHCC), with the average crack width in both FS-SHCC1 and CS-SHCC1 at 14 days remaining below $60 \mu \mathrm{m}$ over the respective strain ranges. Notably a slightly higher average crack width was found for FS-SHCC1 than for CS-SHCC1. This also manifests in the similar number of cracks, which increases roughly linearly with strain to about 30 in the $80 \mathrm{~mm}$ gauge length at $2 \%$ strain. However, a higher maximum crack width is found for FS-SHCC1 (roughly $125 \mu \mathrm{m}$ at $2.5 \%$ strain) than for CS-SHCC1 $(90 \mu \mathrm{m})$. The spacing of cracks can be seen to reduce with increase in tensile strain in both SHCC specimens. Figure 8 shows the formation of cracks in FS-SHCC1 and CS-
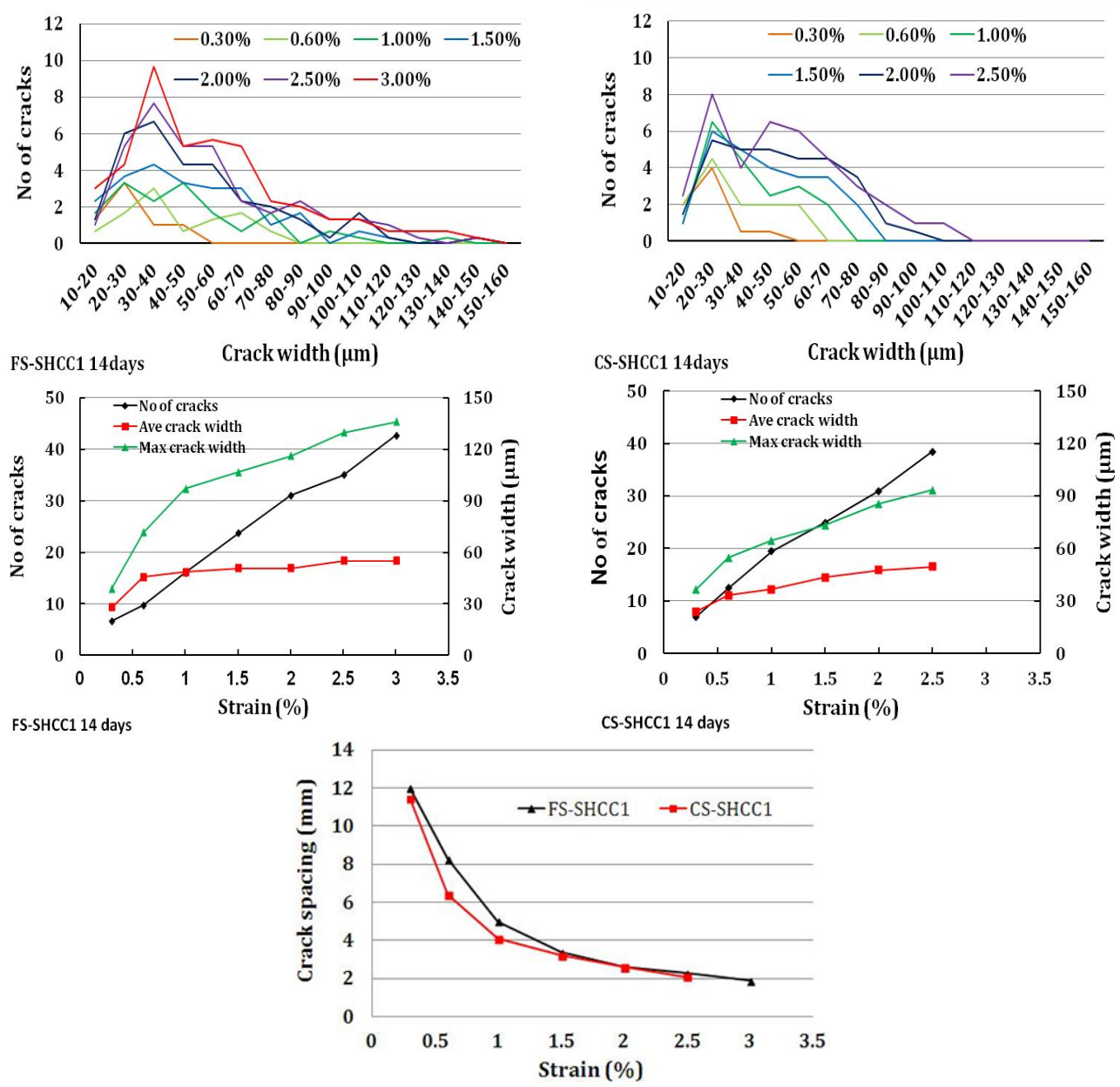

Fig. 7 No.of cracks, crack widths and crack spacing at different strain levels in FS-SHCC1 and CS-SHCC1 at 14 days in the direct tensile test. 

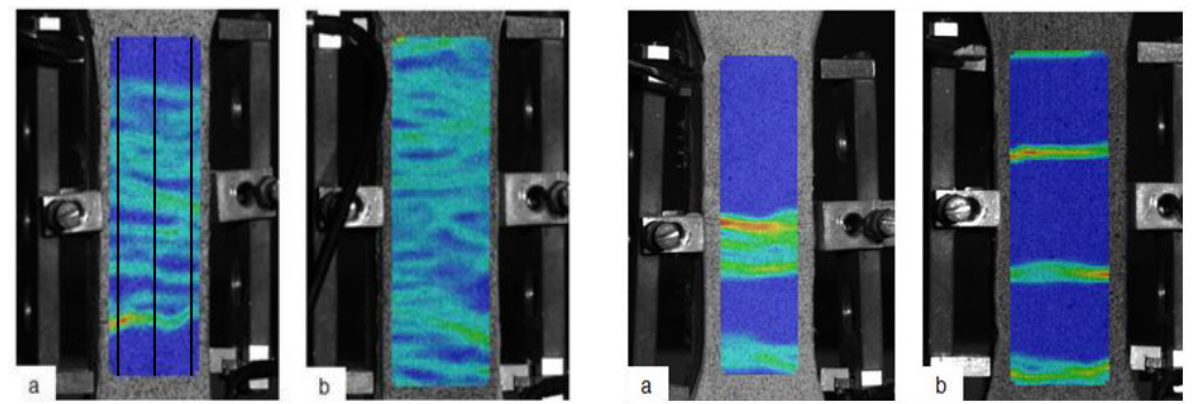

1. 14 days FS-SHCC1 (a) and CS-SHCC1 (b) 2. 28 days FS-SHCC1 (a) and CS-SHCC1 (b)

Fig. 8 Formation of cracks in SHCC specimen during direct tensile test (Paul and van Zijl, 2013a,b).

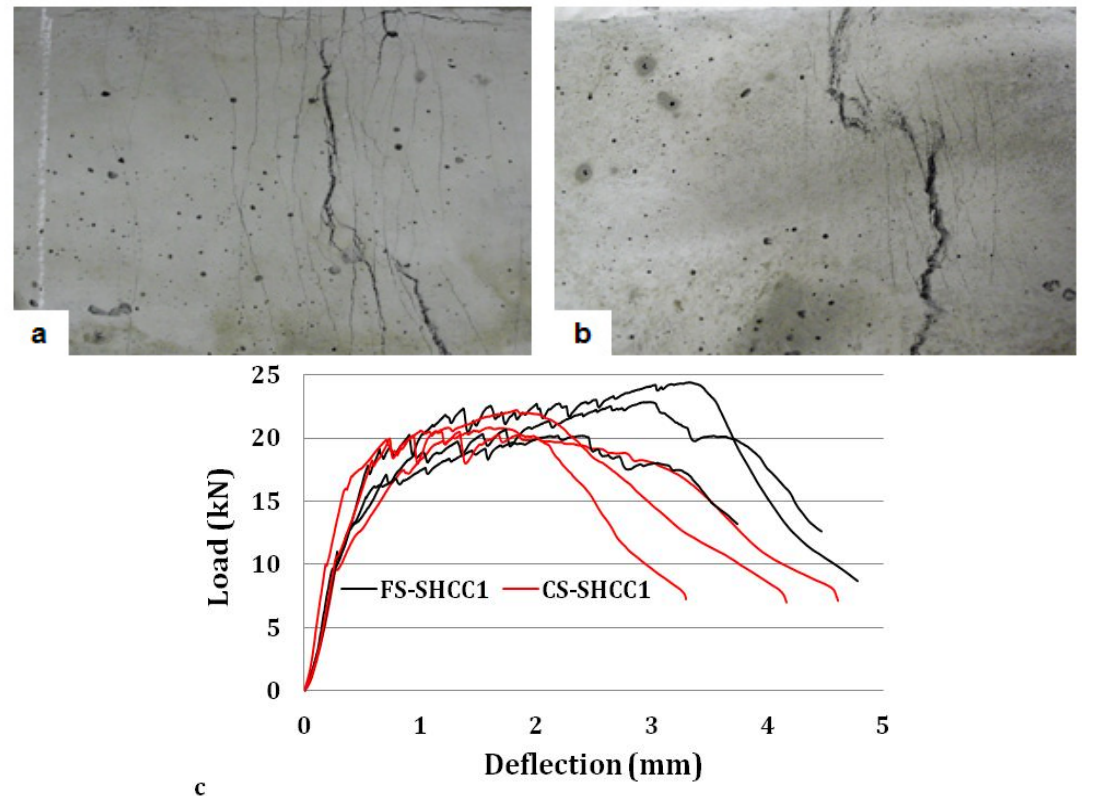

Fig. 9 Cracks in FS-SHCC1 (a) and CS-SHCC1 (b) under ultimate flexural load (c).

SHCC1 at 14 and 28 days. It is worth mentioning that the cracks were counted at the intersections with three lines drawn vertically along the $80 \mathrm{~mm}$ gauge length of the dumbbell specimen, shown in Fig. 8. In this study it was assumed that deformation exceeding $15 \mu \mathrm{m}$ between two points originally roughly $1 \mathrm{~mm}$ apart, were cracks. Note that these deformations were measured with the 3D ARAMIS system during the tensile tests (see Adendorff et al. 2009). Cracks reported in Fig. 7 were measured in the loaded condition of the specimens at the respective strains.

\subsection{Flexural cracks in SHCC specimens}

The total number of cracks and crack widths were also examined in the specimens from the flexural tests. Cracks in both reinforced and unreinforced beams were examined after the test, i.e. in the unloaded state, as opposed to the crack width observations in tensile specimens in the loaded state. In unreinforced SHCC, cracks were examined at the ultimate load state as well as at a deflection level of $1.0 \mathrm{~mm}$. At a deflection level of $1.0 \mathrm{~mm}$, a maximum of 5 cracks of 50 to $100 \mu \mathrm{m}$ wide were found in both FS-SHCC4 and CS-SHCC4 specimens. At the ultimate load more than 10 cracks were observed in both FS and CS-SHCC1 as shown in Fig. 9a and b. Most of the cracks at ultimate level are wider than $0.5 \mathrm{~mm}$ together with a very wide crack $(\geq$ $1.5 \mathrm{~mm}$ ). Table 3 summarises the flexural load levels at which cracks were studied. In general, FS-SHCC specimens showed higher ultimate resistance than the CS-SHCC specimens. The load-deflection responses are shown in Fig. 9c.

\subsection{Flexural cracks in R/SHCC specimens}

$\mathrm{R} / \mathrm{SHCC}$ beams were further used for chloride penetration tests, so only a central $200 \mathrm{~mm}$ length of the bottom

Table 3 Flexural load and deflection level of unreinforced SHCC specimens.

\begin{tabular}{|c|c|c|c|c|c|c|}
\hline Type & \multicolumn{2}{|c|}{ FS-SHCC1 } & \multicolumn{2}{c|}{ CS-SHCC1 } & FS-SHCC4 & CS-SHCC4 \\
\hline Deflection $(\mathrm{mm})$ & 1 & ultimate & 1 & ultimate & 1 & 1 \\
\hline Load $(\mathrm{kN})$ & 18.84 & 23.63 & 20.44 & 21.20 & 17.19 & 14.73 \\
\hline
\end{tabular}


Table 4 Flexural load capacity of R/SHCC specimens at the deflection level of $3.5 \mathrm{~mm}$.

\begin{tabular}{|c|c|c|c|c|c|c|c|c|c|c|c|c|}
\hline Type & \multicolumn{6}{|c|}{ R/FS-SHCC4 } & \multicolumn{6}{|c|}{ R/CS-SHCC4 } \\
\hline Cover & \multicolumn{2}{|c|}{$15 \mathrm{~mm}$} & \multicolumn{2}{|c|}{$25 \mathrm{~mm}$} & \multicolumn{2}{|c|}{$35 \mathrm{~mm}$} & \multicolumn{2}{|c|}{$15 \mathrm{~mm}$} & \multicolumn{2}{|c|}{$25 \mathrm{~mm}$} & \multicolumn{2}{|c|}{$35 \mathrm{~mm}$} \\
\hline $\mathrm{Nr}$ of Bar & 1 & 2 & 1 & 2 & 1 & 2 & 1 & 2 & 1 & 2 & 1 & 2 \\
\hline Load $(\mathrm{kN})$ & 44.4 & 50.2 & 41.1 & 48.7 & 39.1 & 45.3 & 38.1 & 52.7 & 33.3 & 47.1 & 29.9 & 41.2 \\
\hline
\end{tabular}
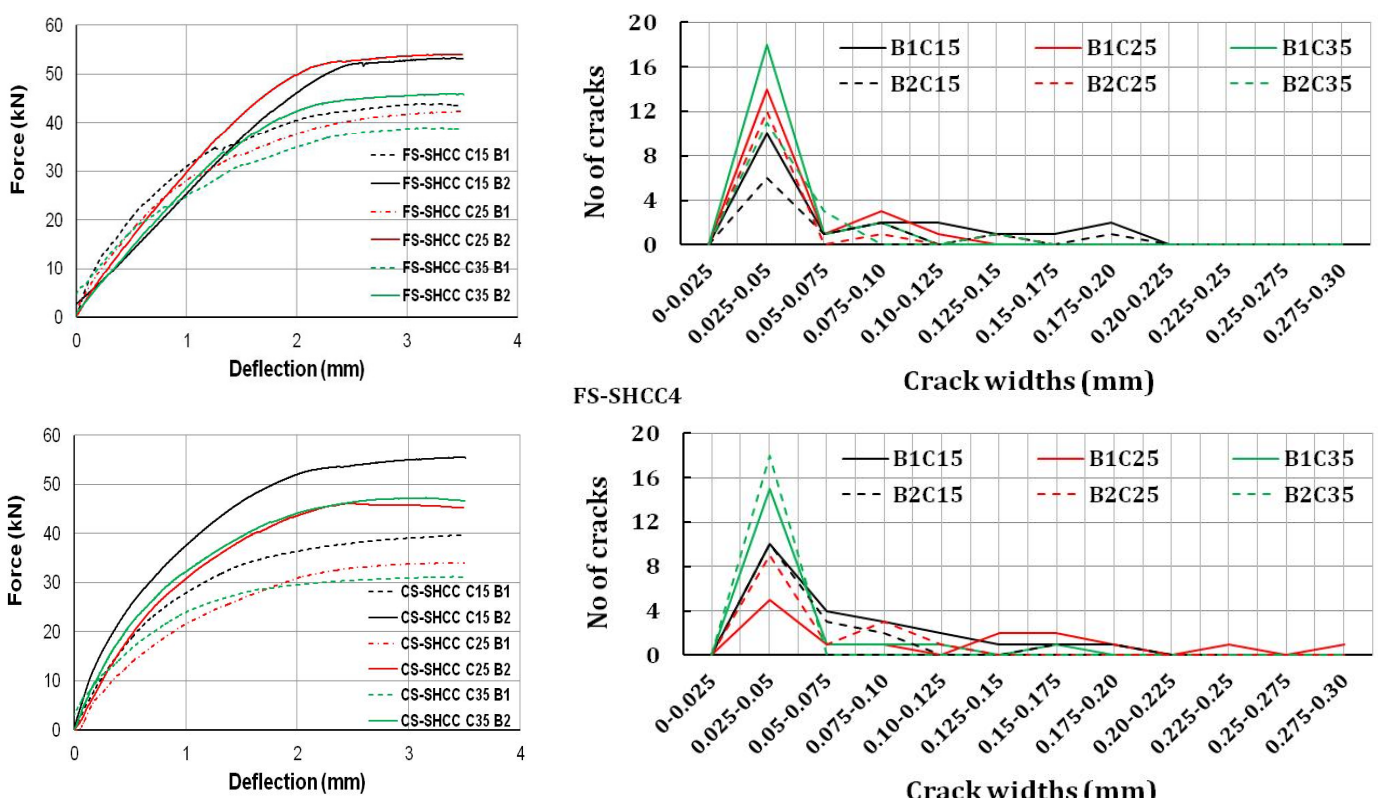

FS-SHCC4

Crack widths $(\mathrm{mm})$

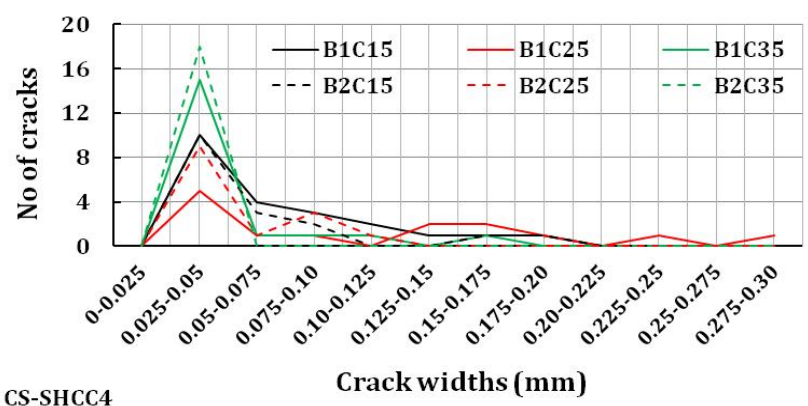

Fig. 10 No of cracks and crack widths in R/SHCC specimens at 14 days in the three point bending test.

face of the specimens was considered for the path of chloride penetration and cracks were measured only in that specific region. Figure $\mathbf{1 0}$ shows the number of cracks and crack widths in that specific region together with load deflection curve. Note that the cracks were observed after unloading from the deflection of $3.5 \mathrm{~mm}$ shown in Fig. 10, leading to an unloaded deflection of roughly $1.5 \mathrm{~mm}$. It was clearly observed that crack widths reduced significantly from the loaded to unloaded state. Figure 11 shows typical crack patterns in the R/FS-SHCC4 and R/CS-SHCC4 specimens with single and double bars, in the unloaded state.

Table 4 shows the flexural resistance of R/SHCC specimens at $3.5 \mathrm{~mm}$ deflection. The crack widths were measured with the aid of a Leica MZ 7.5 microscope, a line width template and using AutoCAD software. Most crack widths were in the range of 50 to $100 \mu \mathrm{m}$ and only a few were found to be in the range 100 to $200 \mu \mathrm{m}$. In the case of double steel bars (B2), most cracks were perpendicular to the steel bar and no parallel cracks were found while in the case of B1, apart from multiple perpendicular cracks, cracking parallel to the steel bar was also observed in most specimens.

In Fig. 12 the average crack spacing is shown, based on the number of cracks per specimen in the $200 \mathrm{~mm}$ observation length. In R/CS-SHCC specimens the crack spacing appears to be in the range $10-14 \mathrm{~mm}$, relatively insensitive to cover depth and with a slightly larger spacing in B2 specimens than in B1 specimens. A slightly lower crack spacing is found for FS-B1 speci- mens (8-11 mm) than for FS-B2 specimens (12-18 mm). In both SHCC beams with one bar, only bending cracks were found. However, with two bars, inclined shear cracks were also observed (see Fig. 11e, f). Due to dominating shear cracks in $\mathrm{B} 2$ specimens, crack spacing in $\mathrm{R} / \mathrm{SHCC}$ is not as uniform as for B1. Another reason may be that crack saturation was not reached in the larger capacity B2 specimens at the $3.5 \mathrm{~mm}$ deflection yet.The FS-B1 specimen crack spacing is insensitive to cover depth, while the B2 specimens with smaller cover depth $(15 \mathrm{~mm})$ had larger crack spacing than those with larger cover depth (35 mm).

From these results it appears that the flexural cracks widths are predominantly less than $100 \mu \mathrm{m}$ in both FS and CS specimens. Figure 12 indicates that larger maximum crack widths were observed in CS beam specimens than in FS specimens. The figure further suggests a trend in the crack width distributions that both FS and CS beams with larger cover depth contain a larger portion of the cracks to below $100 \mu \mathrm{m}$ than those with smaller cover depth. Crack spacing (and thus the total number of cracks) is not significantly influenced by the sand types, cover depths or reinforcement levels tested here, as expressed in Fig. 12. However, the larger crack spacing in R/FS-SHCC with low cover $(15 \mathrm{~mm})$ and relatively high reinforcement level (2 bars) remains to be clarified.

Several authors have indicated a crack width threshold level of 100 - 200 micrometer, below which ingress rates of water and chloride are insignificantly low 


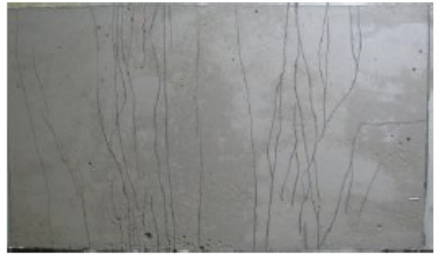

a) FS-SHCC BI

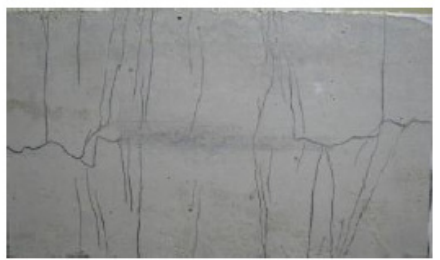

c) FS-SHCC B2

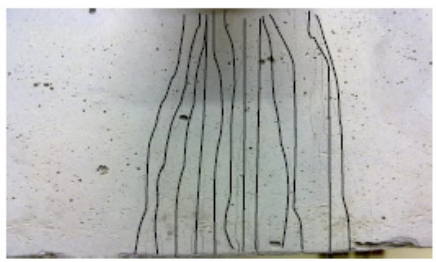

e) Bending cracks in $\mathrm{Bl}$

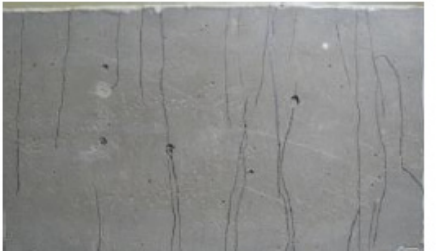

b) CS-SHCC Bl

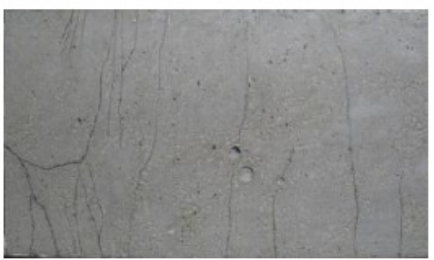

d) $\mathrm{CS}-\mathrm{SHCC}$ B2

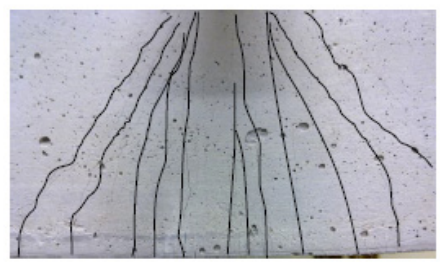

f) Shear and bending cracks in $\mathrm{B} 2$

Fig. 11 Typical flexural cracks pattern in R/SHCC specimens with single and double bars shown on the bottom face (ad) and on the side face $(e, f)$ of the beams.
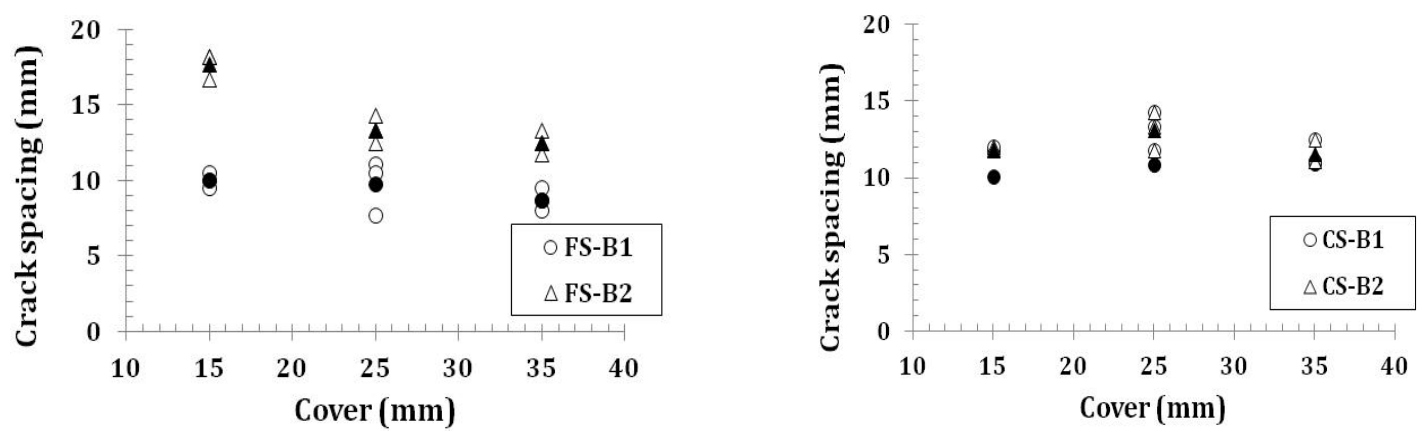

Fig. 12 Crack spacing in (a) FS $-\mathrm{R} / \mathrm{SHCC}$ and (b) $\mathrm{CS}-\mathrm{R} / \mathrm{SHCC}$. Note that the average spacing for each cover depth is shown with a filled-in symbol.

(Mangat and Gurusamy 1987; Aldea et al. 1999). In continued work by the authors, ingress rates in fine cracks, and rate of corrosion in finely cracked R/SHCC are studied, in order to confirm reduced deterioration rates and to quantify these processes for durability design.

\section{Conclusions and recommendations}

In this paper mechanically induced cracks in FS-SHCC and CS-SHCC have been reported extensively, for both uniaxial tension and flexure. The superiority of the tensile and flexural responses compared to normal concrete is clear, and creates the possibility of structural use in suitable applications. From both tensile and flexural tests, the average crack widths in SHCC are below 0.1 $\mathrm{mm}$ under operational loads and beyond, which is considered in current reinforced concrete practise to be a threshold for durability. However, individual cracks with larger widths are found, which requires further investigation into durability of SHCC. In terms of the crack distributions in tension and flexure, the following conclusions can be drawn about the SHCC reported here:

- In both FS and CS-SHCC, a reduction in ultimate tensile strain was found at the age of 28 days compared to that at the age of 14 days. This will be addressed in continued research, to ensure that sufficient ductility is retained throughout structural life. However, the 28 day ultimate strain level in FS and CS-SHCC of roughly $1.5 \%$ may still be sufficient in many structural applications.

- No significant differences were found in terms of the number of cracks and crack widths in unreinforced SHCC containing coarse sand in both tensile and flexural test, compared with SHCC 
containing fine sand.

- In R/SHCC beams that were unloaded after reaching a high, equal deflection level, similar crack width distributions were found in both coarse and fine sand SHCC. The majority of cracks are limited to widths below $0.1 \mathrm{~mm}$.

- At the advanced loading state described above, crack spacing in R/CS-SHCC is insensitive to cover depth in the range $15-35 \mathrm{~mm}$. Due to dominating shear cracks in B2 specimens, in most cases, a slightly larger crack spacing was found for R/SHCC specimens containing two reinforcing bars than those containing a single bar. For beams with a single reinforcement bar the crack spacing was insensitive to the sand types used here.

Ongoing research by the authors quantifies the corrosion rate in cracked R/SHCC and endeavours to verify the postulation that the closely spaced cracks in this composite construction material reduce the corrosion rate, justifying the use of this material to reduce life cycle cost of structures in harsh environments.

\section{References}

Adendorff, C. J., Boshoff, W. P. and van Zijl, G. P. A. G., (2009). "Crack characterisation in SHCC: towards durability assessment." In: G. P. A. G. van Zijl and W. P. Boshoff Eds, Advances in cement based materials., CRC press, 215-221.

Ahmed, S. F. U., (2012). "Flexural performance of repaired reinforced concrete beam containing DFRCC materials." In: Alexander et al. Eds, Concrete Repair, Rehabilitation and Retrofitting III, 1242-1247.

Ahmed, S. F. U., Lu, Y. Y. and Maalej, M., (2013). "Development of ductile fibre reinforced geopolymer composite." In: Van Mier, et al. Eds, 8th International Conference on Fracture Mechanics of Concrete and Concrete Structures (FraMCoS-8), 1064-1071.

Aldea, C. M., Shah, S. P. and Karr, A., (1999). "Effect of cracking on water and chloride permeability of concrete." Journal of Materials in Civil Engineering, 11(3), 181-187.

Benjamin, A. G., (2006). "Material property characterization of ultra-high performance concrete." US Department of transport, Publication No. FHWAHRT-06-103.

Fischer, G. and Li, V. C., (2004). "Effect of fiber reinforcement on the response of structural members." FramCoS, 831-838.

Kelly, A., (1974). "Microstructural parameters of an alligned fibrous composion." Conference on Composites - Standards, Testing and Design, Teddington, National Physical Laboratory, 5-14.

Li, V. C., Stang, H. and Krenchel, H., (1993). "Micromechanics of crack bridging in fibrereinforced concrete." Materials and Structures. 26, 486-494.

Li, V. C., (1993). "From micromechanics to structural
Engineering - The design of cementitious composites for civil engineering applications." J. Struct. Mech. Earthquake Engng, 10, 37-48.

Li, V. C., Mishra, D. K. and Wu, C., (1995). "Matrix design for pseudo strain hardening fibre reinforced cementitious composite." Materials and Structures, 28, 586-595.

Li, V. C., Wang, S. and Wu, C., (2001). "Tensile strainhardening behaviour of polyvinyl alcohol Engineered Cementitious Composite (PVA-ECC)." ACI Materials Journal, 98(6), 483-492.

Li, V. C., (2002). "Large volume, high-performance applications of fibers in Civil Engineering." J.Applied Polymer Science, 83, 660-686.

Mangat, P. S. and Gurusamy, K., (1987). "Chloride diffusion in steel fibre reinforced marine concrete." Cement and Concrete Research, 17(3), 385-396.

Markovic, I., (2006). "High performance hybrid fibre concrete-development and utilisation." $\mathrm{PhD}$ thesis, Technical University Delft, Netherland.

Mc Kee, D.C., (1969). "The properties of an expansive cement mortar reinforced with random wire fibres." $\mathrm{PhD}$ thesis, University of Illinios.

Mihashi, H., Ahmed, S. F. U. and Kobayakawa, A., (2011). "Corrosion of reinforcing steel in fibre reinforced cementitious composites." Journal of Advanced Concrete Technology, 9(2), 159-167.

Mindess, S. and Young. J. F., (1981). "Concrete." Prentice-Hall, Englewood Cliffs, USA.

Miyazato, S. and Hiraishi, Y., (2005). "Transport properties and steel corrosion in ductile fiber reinforced cement composites." Proceedings ICF, Turin, Italy.

Nieuwoudt, P. D., (2012). "Quantifying the cracking behaviour of strain hardening cementbased composites." MSc thesis, Stellenbosch University, South Africa.

Paul, S. C. and van Zijl, G. P. A. G., (2013a). "Mechanical behaviour of strain hardening cementbased composites (SHCC) based on micromechanical design." In: Proceedings of International Conference on Advances in Cement and Concrete Technology in Africa (ACCTA), Johannesburg, South Africa.

Paul, S. C. and van Zijl, G. P. A. G., (2013b). "Strain hardening cement based composite (SHCC) with fine and coarse sand under tensile load and chloride attack." In: Proceedings of $8^{\text {th }}$ International Conference on Fracture Mechanics of Concrete and Concrete Structures (Framcos), Toledo, Spain.

Paul, S. C., Theunissen, A. I. and van Zijl, G. P. A. G., (2013c). "Chloride induced corrosion in cracked reinforced strain hardening cement-based composite (R/SHCC). In: Proceedings of International Conference on Sustainable Construction Materials \& Technologies (SCMT), Kyoto, Japan.

Richard, P. and Cheyrezy, M. H., (1994). "Reactive powder concretes with high ductility and 200800 MPa compressive strength." In: P. K. Mehta ed. 
Concrete Technology: Past, Present, and Future, Proceedings of the V. Mohan Malhotra Symposium, San Francisco, ACI SP-144, 507-518

Romualdi, J. and Mandel, J., (1964). "Tensile strength of concrete affected by uniformly distributed and closely spaced short lengths of wire reinforcement." Journal of the American Concrete Institute, 61(6), 657-671.

Saravanan, J., Suguna, K. and Raghunath, P. N., (2010). "Confined high strength concrete columns: An experimental study." American J. of Engineering and Applied Sciences, 3(1), 133-137.

Sahmaran, M., Li, V. C. and Andrade, C., (2008). "Corrosion resistance performance of steel-reinforced engineered cementitious composite beams." $A C I$ Materials Journal. 105(3), 243-250.

Sahmaran, M., Li, M. and Li. V. C., (2007). “Transport properties of engineered cementitious composite under chloride exposure." ACI Materials Journal, 104(4), 604-611.

Van Zijl, G. P. A. G., (2005). "The role of aggregate in high performance fibre reinforced cement-based composites." Concrete / Beton, (110), 7-13.

Van Zijl, G. P. A. G., (2011). "On ingress into strainhardening cement-based composites (SHCC)." International Journal for Restoration of Buildings and Monuments, 17(6), 1-12.

Wang, S. and Li, V. C., (2006). "Polyvinyl alcohol fiber reinforced engineered cementitious composites:
Material design and performances." In: Proceedings of International workshop on HPFRCC in Structural Applications, Honolulu, Hawaii, USA, May 23-26.

Wang, K., Jansen, D. C., Shah, S. and Karr, A. F., (1997). "Permeability study of cracked concrete." Cerment and Concrete Research, 27(3), 381-393.

Weimann, M. B. and Li, V. C., (2003). "Hygral behavior of Engineered Cementitious Composites (ECC)." International Journal for Restoration of Building and Monuments, 9(5), 515-534.

Wittmann, F. H., Zaho, T., Tian, L., Wang, F. and Wang, L., (2009). "Aspect of durability of strain hardening cement-based composites under imposed strain." In: G. P. A. G. van Zijl and W. P. Boshoff Eds, Advances in Cement-based Materials., CRC press, 173-179.

Yang, Y., Lepech, M. and Li, V. C., (2005). "Selfhealing of engineered cementitious composites under cyclic wetting and drying." In: Proceedings of International Workshop on Durability of Reinforced Concrete under Combined Mechanical and Climatic Loads (CMCL), Qingdao, China, 231-242.

Zhang, P., Wittmann, F. H., Zhao, T. J., Lehmann, E. H., Tian, L. and Vontobel, P., (2010). "Observation and quantification of water penetration into strainhardening cement-based composites (SHCC) with multiple cracks by means of neutron radiography." Nuclear Instruments and Methods in Physics Research A, 620, 414-420. 